\title{
Dissolution Technologies Twentieth Anniversary
}

\author{
Gregory P. Martin \\ Complectors, Consulting LLC, Pottstown, PA 19465
}

e-mail:greg.martin@complectors.com

T his issue marks the twentieth anniversary for Dissolution Technologies, a quarterly, peer-reviewed, open-access journal focused on the interests of the dissolution community. It provides an international forum for dissolution analysts to receive and exchange information on various dissolution topics. It was started in 1994 by Cynthia (Cindy) Brown; Vivian A. Gray became the Managing Director in 2003. The journal features scientific articles addressing hot topics and technology related to dissolution and in vitro testing; reviews of important conferences, workshops, and scientific meetings that feature dissolution topics; book reviews; and a regular column on Questions and Answers.

The inaugural volume addressed the development, validation, and transfer of dissolution methods (1); multicomponent UV-vis analysis in tablet dissolution testing (2); a 25-year retrospective of dissolution (3); a user perspective on dissolution calibration (4); and an overview of automated dissolution (5). Even in the introductory volume, issues related to method lifecycle, instrument calibration, and laborsaving techniques were discussed.

Over the years several topics have appeared multiple times, including method development, apparatus calibration, automation, the use of fiber optics for direct determinations, and concepts associated with in vivo-in vitro correlation (IVIVC) and in vivo-in vitro relationship (IVIVR).

While dissolution is most often performed on tablets and capsules as evidenced by the numerous articles for drugs in these dosage forms, there have also been many articles devoted to other dosage forms such as semisolids, transdermal products, nutritional supplements, extendedrelease products, veterinary products, and chewing gums.

As part of its mission to exchange information, Dissolution Technologies has a long tradition of summarizing content from scientific meetings and workshops where dissolution has been a major component of the discussion. This includes meetings with various sponsors such as the FDA, FIP, WHO, USP, AAPS, and CRS. Meeting topics have ranged from IVIVC and biowaivers to in vitro testing of novel dosage forms and the role of dissolution in $\mathrm{QbD}$ and product lifecycle.

A regular column, the Question and Answer Section, has appeared in the journal since 1999. Prepared by scientists at the USP, it provides practical advice with compendial insight.

The journal has published several themed issues on topics of particular interest that have proved to be very popular (Table 1). IVIVC is the topic for the next themed issue, which will be published in May 2015.

Dissolution Technologies has followed the AAPS In Vitro Release and Dissolution Testing Focus Group (IVRTDFG) since its inception. Vivian Gray, Managing Director of Dissolution Technologies, was one of the founding organizers of the focus group and an ongoing, strong supporter. The group members were asked to identify some of their favorite articles, shown in Table 2.

Over time, the journal content has changed to reflect the changes in regulations and industry practice. Calibration of dissolution apparatus, the most frequently cited topic, has evolved from (presumably) straightforward application of the calibrator tablet test to the more recent introduction of the Performance Verification Test with its companion Dissolution Toolkit and the FDA guidance (6). Correspondingly, the content in Dissolution Technologies has evolved from a user's perspective in the first volume (4) to the special edition on industry trends for performance verification testing and enhanced mechanical calibration in 2011. Similarly, the content of the journal has tracked the changes in establishing specifications, issues with poorly water-soluble compounds and the introduction of the Biopharmaceutics Classification System (BCS), the changes in expectations regarding IVIVCs, and the introduction and subsequent revisions to USP General Chapter <1092> The Dissolution Procedure: Development and Validation.

Dissolution Technologies is an invaluable resource for those interested in dissolution. The fact that it is open and searchable makes it useful not only for practitioners in the field, but has expanded access to those for whom this information might not be readily available, such as graduate students and scientists in smaller companies. We look

Table 1. Topics for Themed Issues of Dissolution Technologies

\begin{tabular}{ll}
\hline \multicolumn{1}{c}{ Topic } & \multicolumn{1}{c}{ Issue } \\
\hline Fiber Optics & November 2003 \\
\hline Apparatus 4 & May 2005, November 2011 \\
\hline Semisolids & November 2010 \\
\hline Biorelevant Dissolution & August 2009 \\
\hline Automation & May 2013 \\
\hline Calibration and Variables & February 2005 \\
\hline Industry Trends for PVT and Enhanced & May 2011 \\
Mechanical Calibration & \\
\hline
\end{tabular}


Table 2. AAPS In Vitro Release and Dissolution Testing Focus Group Nominations for Favorite Articles

\begin{tabular}{ll}
\hline \multicolumn{1}{c}{ Title } & Author \\
\hline Manual In Situ Fiber Optic Dissolution Analysis in Quality Control & C.Schatz, M. Ulmschneider, R. Altermatt, S. Marrer, H. Altorfer \\
\hline In Situ Dissolution Testing using Different UV Fiber Optic Probes and Instruments & X. Lu, R. Lozano, P.Shah \\
\hline Dissolution Profile Comparison Using Similarity Factor, $f_{2}$ & V.P.Shah, Y.Tsong, P.Sathe, R. L.Williams \\
\hline Two-Tier Dissolution Testing & V.A.Gray \\
\hline Steps for Development of a Dissolution Test for Sparingly Water-Soluble Drug Products & C. Noory, N.Tran, L. Ouderkirk, V.Shah \\
\hline Perturbation Study of Dissolution Apparatus Variables: A Design of Experiment Approach & J.Eaton, G.Deng, W.W. Hauck, W.Brown, R. G. Manning, S.Wahab \\
\hline
\end{tabular}

forward to this journal continuing to serve the dissolution community by keeping them informed on major topics of interest in the field of dissolution and seeking out high quality articles to keep its readers well informed.

\section{REFERENCES}

1. Peterson, D. L. Development, Validation, and Transfer of Dissolution Methods. Dissolution Technol. 1994, 1 (1), 3.

2. Bayerbach, S. Multicomponent UV-Visible Analysis in Tablet Dissolution Testing. Dissolution Technol. 1994, 1 (1), 4-5, 8-9.

3. Hanson, W. A. Dissolution-25 Years. Dissolution Technol. 1994, 1 (1), 6-7, 11.
4. Skoug, J. W. Calibration of Dissolution Rate Apparatuses: A User's Perspective. Dissolution Technol. 1994, 1 (2), 3-5.

5. Buechsenschuetz, R.; Correia, S. Automated Dissolution Testing-A Brief Overview. Dissolution Technol. 1994, 1 (2), 6-9.

6. The Use of Mechanical Calibration of Dissolution Apparatus 1 and 2-Current Good Manufacturing Practice (CGMP); Guidance for Industry; U.S. Department of Health and Human Services, Food and Drug Administration, Center for Drug Evaluation and Research (CDER), U.S. Government Printing Office: Washington, DC, 2010. 